\title{
Design of Area-Efficient, Low-Quiescent-Current LDOs for Chip-Level Power Management
}

\author{
Tsz Yin Man ${ }^{*}$, Philip K. T. Mok and Mansun Chan \\ Department of Electronic and Computer Engineering, Hong Kong University of Science and Technology \\ E-mail: eesm@ece.ust.hk
}

\begin{abstract}
In this paper, design methodology of area-efficient and low-quiescent-current low-dropout regulators (LDOs) for chip-level power management is proposed. As LDO chip size is dominated by the large size power transistor, guidelines are given to minimize its size when design specifications such as the dropout voltage, the minimum input voltage and the maximum load current are given. The reduced power transistor size also helps to maintain satisfactory error amplifier slew-rate at low quiescent current consumption. Stability of LDO designed under the proposed methodology is thoroughly studied. Extensive simulations are done to verify the stability study.
\end{abstract}

\section{INTRODUCTION}

Recently, chip-level power management with embedded low-dropout regulators (LDOs) has drawn a great attention among the electronic industry and research community [1-2] To minimize the chip size and power consumption, the embedded LDOs should have high area efficiency and low quiescent current consumption. However, most of LDOs [3-7] are developed with the use of a large value output capacitor that is normally ranged from few hundreds $\mathrm{nF}$ to several tens of $\mu \mathrm{F}$. Integrating such large value output capacitor with LDOs for chip-level power management is definitely not an area-efficient approach. To develop LDOs with very small output capacitance that is mainly contributed by the metal routing used for chip-level power distribution, different LDO topologies have been proposed [4 \& 8]. Even those topologies can greatly minimize the total value of on-chip compensation capacitors, the use of on-chip capacitors still inevitably degrades LDO area efficiency that is very important in applications [1-2] where multiple LDOs are used. Recently, an area-efficient LDO has been proposed for microprocessor application [9]. As fast load regulation is required, the quiescent current of LDO in [9] is around $6-\mathrm{mA}$ at $100-\mathrm{mA}$ full load current (e.g. $94 \%$ current efficiency). However, this current efficiency is a little bit too large for LDOs used in battery-powered mobile systems.

In this paper, design of area-efficient and low-quiescentcurrent LDOs is thoroughly discussed. Section II presents the design methodology of LDOs with high area efficiency and low quiescent current consumption. Stability of such LDOs is carefully studied in Section III. Finally, conclusion is given in Section IV.
II. DESIGN OF AREA-EFFICENT AND LOW-QUIESCENT-CURRENT LDOS

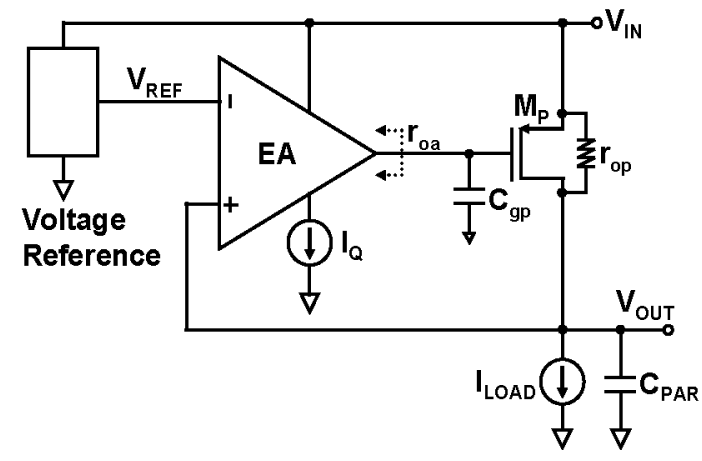

Fig. 1 Schematic of a generic LDO

Fig. 1 shows a generic LDO consisting of an error amplifier (EA), a PMOS power transistor $\left(M_{\mathrm{P}}\right)$, and a voltage reference that can be bandgap reference [10-13]. Small signal elements are included in Fig. 1 for the stability analysis in Section III. The current source ( $\mathrm{I}_{\mathrm{LOAD}}$ ) is used to model the current consumed by the load circuit. Another current source $\left(I_{Q}\right)$ is used to illustrate that quiescent current is defined as the current consumed by the control circuit of LDO (e.g. EA) but not the current delivered by the power transistor to load (e.g. $\mathrm{I}_{\mathrm{LOAD}}$ ).

To reduce the quiescent current without degrading the error amplifier slew-rate (SR), which is defined as the $\mathrm{I}_{\mathrm{Q}}$ divided by the gate capacitance of power transistor $\left(\mathrm{C}_{\mathrm{gp}}\right.$, e.g. $\left.\mathrm{SR}=\mathrm{I}_{\mathrm{Q}} \mathrm{C}_{\mathrm{gp}}\right)$, the size of power transistor should be minimized such that the $\mathrm{C}_{\mathrm{gp}}$ can be reduced. Moreover, chip size of LDO is dominated by the large size power transistor. Minimizing the size of power transistor not only improves LDO area efficiency, it also improves SR of error-amplifier without increasing the $\mathrm{I}_{\mathrm{Q}}$ of $\mathrm{LDO}$.

The size of power transistor can be minimized by designing it to operate in linear region at a given dropout voltage $\left(\mathrm{V}_{\mathrm{DO}}\right)$, which is defined as the minimum pass-transistor source-to-drain voltage to maintain output voltage regulation at maximum load current $\left(\mathrm{I}_{\mathrm{LOAD} M A X}\right)$ and minimum input voltage $\left(\mathrm{V}_{\mathrm{IN} \_ \text {MIN }}\right)$. Size or aspect ratio $\left(\mathrm{W}_{\mathrm{p}} / \mathrm{L}_{\mathrm{P}}\right)$ of power 
transistor can be calculated with equation (1) shown in the following

$$
\frac{\mathrm{W}_{\mathrm{p}}}{\mathrm{L}_{\mathrm{P}}}=\frac{\mathrm{I}_{\text {LOAD_MAX }}}{\mu_{\mathrm{P}} \mathrm{C}_{\text {OXP }} \mathrm{V}_{\text {DO }}\left(\mathrm{V}_{\text {IN_MIN }}-\mathrm{V}_{\text {OEA_MIN }}-\left|\mathrm{V}_{\text {THP }}\right|-\mathrm{V}_{\mathrm{DO}} / 2\right)}(1),
$$

where $\mu_{\mathrm{P}}, \mathrm{C}_{\mathrm{OXP}}$, and $\mathrm{V}_{\mathrm{THP}}$, are mobility, gate capacitance per unit area, and threshold voltage, of $\mathrm{M}_{\mathrm{P}}$, respectively. As illustrated in Fig. 2, the term $V_{\mathrm{OEA}}$ MIN is the minimum error amplifier output voltage at which the error amplifier is still operated in high-gain region. To minimize the $\mathrm{V}_{\mathrm{OEA} \text { MIN }}$ such that the aspect ratio of power transistor can be further minimized, transistors at the output of error amplifier should be designed to have small drain-to-source saturation voltage. This can be achieved by designing the output transistors with very small overdrive voltage. Although small overdrive voltage requires the output transistors with large aspect ratio, which unavoidably increases the internal node capacitance of error amplifier, slew-rate of error amplifier is not degraded as its slew-rate is limited at its output by the gate capacitance of $\mathrm{M}_{\mathrm{P}}$. Power transistor worked in linear region may degrade the loop gain and hence the regulation performance of LDO operated at the dropout situation. However, it saves huge chip area compared to LDOs with power transistor operated in saturation region. Table I summarizes the aspect ratio of power transistor designed by the "linear region" approach and the "saturation region" approach at different CMOS technologies where transistor parameters are obtained at [14]. The $\mathrm{V}_{\text {DO, }}, \mathrm{V}_{\mathrm{IN} \text { MIN }}, \mathrm{V}_{\mathrm{OEA} \text { MIN }}$, and $\mathrm{I}_{\text {LOAD MAX }}$ are assumed to be $0.2 \mathrm{~V}, 1.2 \mathrm{~V}, 0.1 \mathrm{~V}$, and $50 \mathrm{~mA}$, respectively.
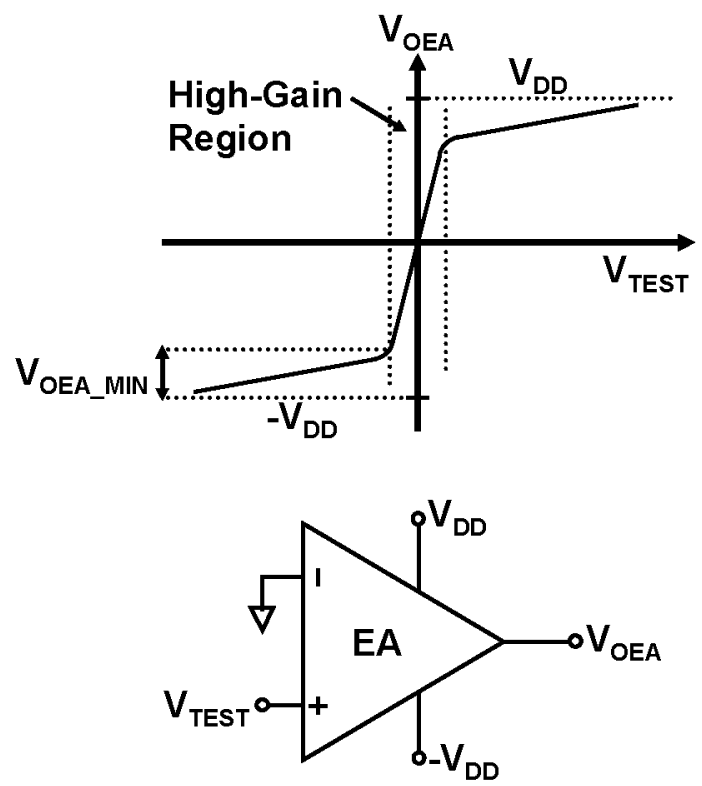

Fig. 2 Graphical illustration of $V_{O E A}$ MN that is defined as the minimum error amplifier output voltage at which the error amplifier is sill operated in high gain region.
TABLE I

ASPECT RATIO OF MP WITH "LINEAR REGION" APPROACH AND "SATURATION REGION" APPROACH AT DIFFERENT CMOS TECHNOLOGIES.

\begin{tabular}{|c|c|c|}
\hline CMOS Technology & $\begin{array}{c}\text { Aspect Ratio at } \\
\text { "Linear Region" } \\
\text { Approach }\end{array}$ & $\begin{array}{c}\text { Aspect Ratio at } \\
\text { "Saturation Region" } \\
\text { Approach }\end{array}$ \\
\hline $0.13-\mu \mathrm{m}$ & $\sim 5500$ & $\sim 25640$ \\
\hline $0.18-\mu \mathrm{m}$ & $\sim 6800$ & $\sim 29300$ \\
\hline $0.25-\mu \mathrm{m}$ & $\sim 10400$ & -41600 \\
\hline
\end{tabular}

\section{STABILITY ANALYSIS}

To analyze stability of LDO shown in Fig. 1, loop-gain analysis is performed in this section. It is found that there are two left-half-plane (LHP) poles

$$
\mathrm{P}_{\mathrm{OEA}}=\frac{1}{\mathrm{r}_{\mathrm{oa}} \cdot \mathrm{C}_{\mathrm{gp}}}
$$

and

$$
\mathrm{P}_{\mathrm{OLDO}}=\frac{1}{\mathrm{r}_{\mathrm{op}} \cdot \mathrm{C}_{\mathrm{PAR}}}
$$

where $r_{o a}$ is the output resistance of error amplifier and $r_{o p}$ is the drain resistance of power transistor. $\mathrm{C}_{\mathrm{PAR}}$ is the parasitic capacitance at the output of LDO contributed by the metal routing used for chip-level power distribution. The pole $\mathrm{P}_{\mathrm{OEA}}$ is formed at the output of error amplifier and the pole $\mathrm{P}_{\text {OLDO }}$ is at the output of LDO. The pole $\mathrm{P}_{\mathrm{OEA}}$ is located at much lower frequency than the pole $\mathrm{P}_{\text {OLDO. }}$ This is because the $r_{o a}$ is much larger the $r_{o p}$ due to the fact that channel length of transistors used in error amplifier is normally several times larger than the minimum feature size of a given CMOS technology but channel length of power transistor follows the minimum feature size for smaller chip size. Moreover, the $\mathrm{C}_{g p}$ and the $\mathrm{C}_{\mathrm{PAR}}$ is normally in the same order of magnitude (e.g. $\sim$ pF). The corresponding locations of poles $\mathrm{P}_{\mathrm{OEA}}$ and $\mathrm{P}_{\text {OLDO }}$ are illustrated in Fig. 3. The location of pole $\mathrm{P}_{\mathrm{OEA}}$ is relatively fixed. However, the pole $\mathrm{P}_{\text {OLDo }}$ has a strong dependence on load current (e.g. $r_{\mathrm{op}} \propto 1 / \mathrm{I}_{\text {LOAD }}$ ). When load current is large, stability of LDO is guaranteed as the pole $\mathrm{P}_{\text {OLDO }}$ is located far away from the pole $\mathrm{P}_{\mathrm{OEA}}$ and the unity-gain frequency $\left(f_{U G}\right)$. Equation (4) gives the $f_{U G}$ expression

$$
\mathbf{f}_{\mathrm{UG}}=\frac{\mathbf{g}_{\mathrm{ma}} \mathbf{g}_{\mathrm{mp}} \mathbf{r}_{\mathrm{op}}}{\mathrm{C}_{\mathrm{gp}}}
$$

where the $g_{m a}$ and the $g_{m p}$ are transconductance of error amplifier and power transistor, respectively. When load 
current is reduced, the pole $\mathrm{P}_{\mathrm{OLDO}}$ is moved from high frequency regime to low frequency region. Once the $\mathrm{P}_{\mathrm{OLDO}}$ becomes smaller than the $\mathrm{f}_{\mathrm{UG}}$, LDO stability is very difficult to guarantee. In other words, the LDO is stable when the pole $P_{\text {OLDO }}$ is larger than the $f_{U G}$. Equation (5) shows this stability criterion (e.g. $P_{\mathrm{OLDO}}>\mathrm{f}_{\mathrm{UG}}$ ) by using the equations (3) and (4)

$$
\frac{\mathrm{C}_{\mathrm{gp}}}{\mathrm{C}_{\mathrm{PAR}}}>\mathrm{g}_{\mathrm{ma}} \mathrm{r}_{\mathrm{op}} \mathrm{g}_{\mathrm{mp}} \mathrm{r}_{\mathrm{op}}
$$

The term at right-hand-side of (5) has very strong dependence on load current [e.g. $\mathrm{g}_{\mathrm{ma}} \mathrm{r}_{\mathrm{opg}} \mathrm{g}_{\mathrm{mp}} \mathrm{r}_{\mathrm{op}} \propto 1 /\left(\mathrm{I}_{\mathrm{LOAD}}\right)^{3 / 2}$ ]. Stability of LDO can only be guaranteed down to certain value of load current. Large $\mathrm{C}_{\mathrm{PAR}}$ caused by the on-chip metal routing for power distribution also hurts LDO stability. Although a larger $C_{g p}$ due to the use of larger size power transistor helps to improve LDO stability, chip area efficiency is inevitably increased

To quantitatively evaluate stability of LDO at different load-current levels, extensive simulations are done at $0.13-\mu \mathrm{m}$ CMOS technology. The error amplifier shown in Fig. 4 is used in the simulations. The current source $\mathrm{I}_{\mathrm{Q}}$ of that amplifier is around $10 \mu \mathrm{A}$ such that the quiescent current of LDO is around $20 \mu \mathrm{A}$ Channel length of transistors in that error amplifier is designed to be four times the minimum feature size of $0.13-\mu \mathrm{m}$ CMOS technology (e.g. $\mathrm{L}=0.52 \mu \mathrm{m}$ ). The aspect ratio of transistors in that error amplifier is designed to make the $\mathrm{V}_{\text {OEA MIN }}$ equal to $\sim 0.1 \mathrm{~V}$. The actual aspect ratio can be calculated using equation (6) shown in the following

$$
\frac{\mathrm{W}}{\mathrm{L}}=\frac{\mathrm{I}_{\mathrm{Q}}}{\mu \mathrm{C}_{\mathrm{OX}}\left(\mathrm{V}_{\text {OEA_MIN }}\right)^{2}}
$$

Channel length of power transistor is designed to be the minimum feature size of $0.13-\mu \mathrm{m}$ CMOS technology (e.g. $\mathrm{L}=0.13 \mu \mathrm{m}$ ). The aspect ratio of power transistor calculated by the "linear region" approach shown in Table I is adopted.

Fig. 5 shows the simulated open loop-gain response of LDO operated at three different current levels (e.g. $50 \mathrm{~mA}$, $5 \mathrm{~mA}$, and $500 \mu \mathrm{A}$ ) in which the $\mathrm{r}_{\mathrm{op}}$ is small enough to make the pole $\mathrm{P}_{\mathrm{OLDO}}$ far away from the unity-gain frequency. The phase margin (PM) at $50 \mathrm{~mA} \mathrm{I}_{\mathrm{LOAD}}$ is $\sim 100$ degree, at $5 \mathrm{~mA}$ $\mathrm{I}_{\text {LOAD }}$ is $\sim 81$ degree, and at $500 \mu \mathrm{A} \mathrm{I}_{\text {LOAD }}$ is $\sim 71$ degree. As the power transistor is designed to operate in linear region at the dropout condition, the loop gain is decreased from $-46 \mathrm{~dB}$ at $500 \mu \mathrm{A} \mathrm{I}_{\mathrm{LOAD}}$ to $\sim 12 \mathrm{~dB}$ at $50 \mathrm{~mA} \mathrm{I}_{\mathrm{LOAD}}$.

Fig. 6 shows the simulated open loop-gain response of LDO operated at another three different current levels (e.g. $50 \mu \mathrm{A}, 10 \mu \mathrm{A}$, and $5 \mu \mathrm{A}$ ) in which the $\mathrm{r}_{\mathrm{op}}$ increases rapidly such that the pole $\mathrm{P}_{\text {OLDO }}$ is moved toward the unity-gain frequency. The PM at $50 \mu \mathrm{A} \mathrm{I}_{\mathrm{LOAD}}$ is $\sim 63$ degree. When $\mathrm{I}_{\mathrm{LOAD}}$ is at $10 \mu \mathrm{A}$, the $\mathrm{PM}$ is decreased to -32 degree. The $\mathrm{PM}$ at $5 \mu \mathrm{A}$ $\mathrm{I}_{\mathrm{LOAD}}$ is just -2 degree that means the pole $\mathrm{P}_{\mathrm{OLDO}}$ is at the $\mathrm{f}_{\mathrm{UG}}$.

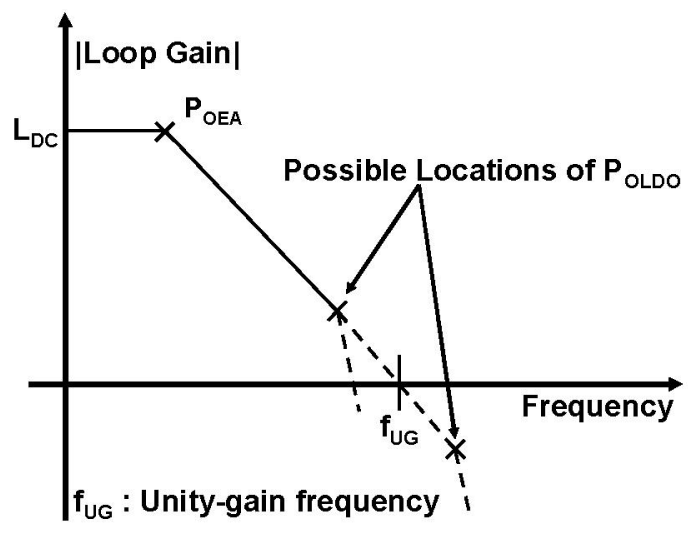

Fig. 3 Open loop-gain magnitude plot of LDO appeared in Fig. 1.

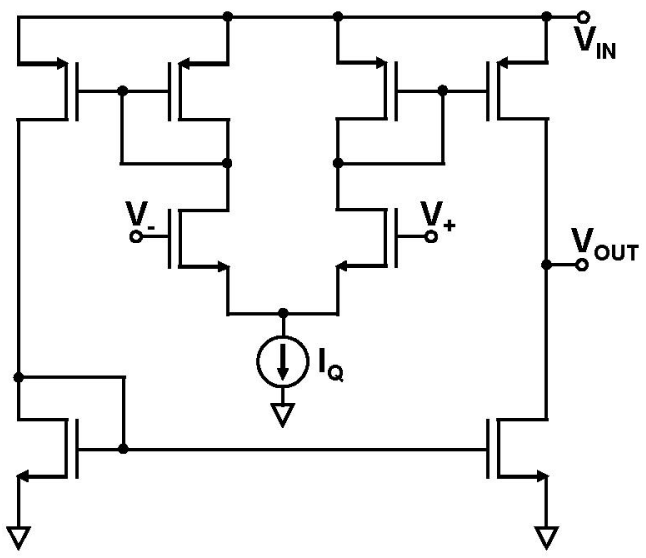

Fig. 4 Schematic of error amplifier used in LDO simulations.
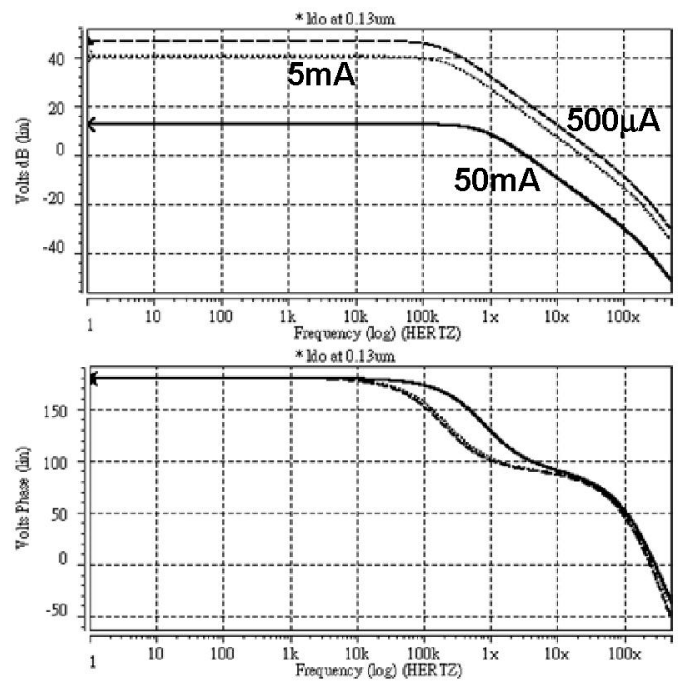

Fig. 5 Simulated open loop-gain response of LDO operated at three different current levels such as $50 \mathrm{~mA}, 5 \mathrm{~mA}$ and $500 \mu \mathrm{A}$. 

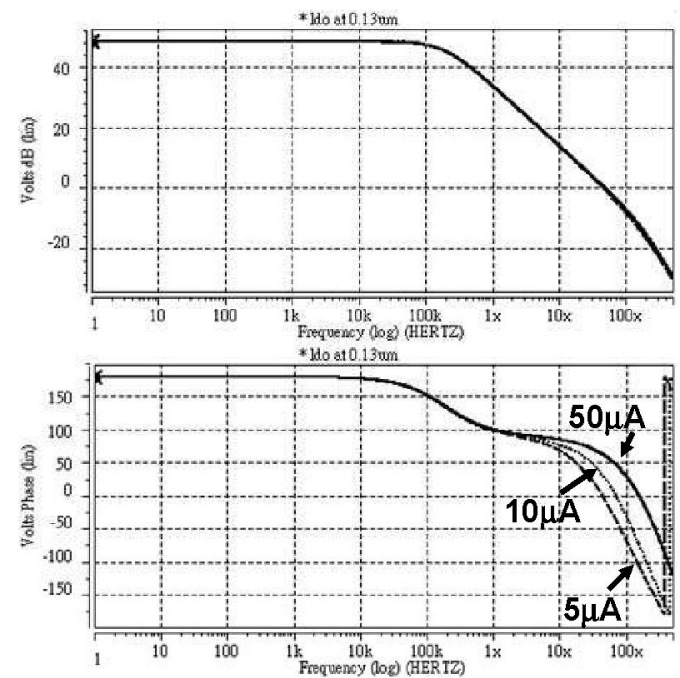

Fig. 6 Simulated open loop-gain response of LDO operated at another three different current levels such as $50 \mu \mathrm{A}, 10 \mu \mathrm{A}$ and $5 \mu \mathrm{A}$.

\section{CONCLUSION}

Design methodology of area-efficient and low-quiescentcurrent LDOs for chip-level power management is given in this paper. By designing the power transistor operated in linear region at the dropout condition, aspect ratio of power transistor is reduced by almost four times when compared to the power transistor designed to operate in saturation region. This significantly aspect ratio reduction helps to improve error amplifier slew-rate without increasing the quiescent current consumption. It is also found that stability of LDO designed under the proposed guideline has a minimum load current requirement. According to the stability criterion derived in this work, the minimum load current requirement can be released by using a larger size power transistor.

\section{REFERENCES}

[1] H. Eul, "ICs for mobile multimedia communications," IEEE ISSCC, pp. 21-39,2005

[2] D. D. Buss, "Technology in internet age," IEEE ISSCC, pp. 18-21, 2002

[3] C. K. Chava and J. Silva-Martinez, "A frequency compensation scheme for LDO voltage regulators," IEEE TCAS-I, vol.51, pp.1041-1050, June 2004.

[4] K. N. Leung and P. K. T. Mok, "A capacitor-free CMOS low-dropout regulator with damping-factor-control frequency compensation," IEEE $J S S C$, vol.38, pp. 1691-1702, October 2003

[5] G. A. Rincon-Mora, "Active multiplier in Miller-compensated circuits," IEEE JSSC, vol. 35, pp. 26-32, January 2000.

[6] G. A. Rincon-Mora and P. E. Allen, "Optimized frequency-shaping circuit topologies for LDOs," IEEE TCAS-II, vol. 45, pp. 703-708, June 1998.

[7] G. A. Rincon-Mora and P. E. Allen, "A low-voltage, low quiescent current, low drop-out regulator," IEEE JSSC, vol. 33, pp. 36-44, January 1998

[8] S. K. Lau, P. K. T. Mok and K. N. Leung, "A Low-Dropout Regulator for SoC with Q-Reduction," IEEE JSSC, vol. 42, pp. 658-664, March 2007.

[9] P. Hazucha, T. Kamik, B.A. Bloechel, C. Parsons and S. Borkar, "Area-efficient linear regulator with ultra-fast load regulation," IEEE JSSC, vol.40, pp.933-940, April 2005.

[10] K. N. Leung, P. K. T. Mok, and C. Y. Leung, "A 2-V 23-T A 5.3-ppm/C curvature-compensated CMOS bandgap reference," IEEE JSSC, vol. 38, pp. 561-564, March 2003

[11] K. N. Leung and P. K. T. Mok, "A sub1-V 15-ppm/ C CMOS bandgap voltage reference without requiring low threshold voltage device," IEEE JSSC, vol. 37, pp. 526-530, April 2002

[12] H. Banba, H. Shiga, A. Umezawa, T. Miyaba, T. Tanzawa, S. Atsumi, and K. Sakui, "A CMOS bandgap reference circuit with subl-V operation," IEEE JSSC, vol. 34, pp. 670-674, May 1999.

[13] B.-S. Song and P. R. Gray, "A precision curvature-compensated CMOS bandgap reference," IEEE JSSC, vol. 18, pp. 634-643, December 1983.

[14] http:/www.mosis. org 